\title{
Time course of timing reprogramming in interception is modulated by uncertainty on velocity alteration
}

\author{
Luis Teixeira \\ Mariana Franzoni
}

https://doi.org/10.5628/rpcd.05.02.167

\author{
University of São Paulo \\ School of Physical Education and Sport \\ Brazil
}

\begin{abstract}
Reprogramming of interceptive actions is required when an abrupt unexpected modification in target velocity takes place. In such a situation, the original timing specifications have to be replaced by other ones appropriate for the new characteristics of the target motion in a short period of time. In this study, we contrasted two sources of uncertainty on target velocity modification in an interceptive task, probability and direction of change, and analyzed the time course of movement timing reprogramming. Participants tried to synchronize the action of hitting a hemiball with the arrival of a moving target at the end of an electronic trackway. The target was initially displaced at a constant velocity of $3 \mathrm{~m} / \mathrm{s}$, and in some trials its velocity was unexpectedly changed to $2 \mathrm{~m} / \mathrm{s}$ or $4 \mathrm{~m} / \mathrm{s}$ at different moments before interception. Participants were assigned to one of two groups: $25 \%$ or $50 \%$ probability of target velocity alteration, with both groups facing conditions of uni and bidirectional velocity change. The results showed a gradual increment of temporal accuracy as a function of longer times after velocity change, revealing the continuous nature of timing reprogramming. The lowest uncertainty condition led to the best movement reprogramming, producing more accurate timing responses throughout situations of changed velocity.
\end{abstract}

Key Words: movement reprogramming, continuous models, moving targets, sensorimotor control.

\begin{abstract}
RESUMO
O curso de tempo da reprogramação temporal em tarefa interceptativa é modulado pela incerteza sobre a mudança de velocidade

Quando ocorre uma mudança abrupta e inesperada na velocidade de um alvo móvel em tarefas interceptativas, torna-se necessária a reprogramação do ato motor. Em tal situação, as especificações originais de temporização do movimento devem ser substituídas por outras apropriadas às novas características de deslocamento do alvo em um curto intervalo de tempo. Neste estudo contrastámos duas fontes de incerteza sobre a modificação de velocidade do alvo em uma tarefa interceptativa, probabilidade e direção de mudança, e analisamos o curso de tempo para reprogramação do componente temporal. Os participantes tentaram sincronizar a ação de contatar uma hemibola com a chegada de um estímulo móvel ao final de um trilho eletrônico. O estímulo foi deslocado inicialmente com uma velocidade constante de $3 \mathrm{~m} / \mathrm{s}$, e em algumas tentativas sua velocidade foi inesperadamente alterada para $2 \mathrm{~m} / \mathrm{s}$ ou para 4 $\mathrm{m} / \mathrm{s}$ em diferentes momentos antes da interceptação. Os participantes foram distribuídos em dois grupos: $25 \%$ ou $50 \%$ de probabilidade de mudança de velocidade, sendo que ambos os grupos foram submetidos às condiçốes de mudança unidirecional e bidirecional de velocidade. Os resultados mostraram um aumento gradual da precisão temporal em função de períodos mais longos após a mudança de velocidade, revelando a natureza contínua da reprogramação motora. A condição de menor incerteza levou à melhor reprogramação, resultando em respostas temporalmente mais precisas através das situaçôes de mudança de velocidade.
\end{abstract}

Palavras-chave: reprogramação motora, modelos contínuos, alvos móveis, controle sensoriomotor. 


\section{INTRODUCTION}

Voluntary modification of movement specifications in ongoing actions is required when large-scale errors are provoked by nonanticipated changes in important aspects of the environment. This situation is more commonly seen in open skills, like interceptive tasks, wherein the displacement profile of a ball is unexpectedly changed after its contact with an irregular terrain, with the net separating the two halves of a court, or by the spin applied to the ball rendering its displacement different from that expected after contact with the ground. In those circumstances, the participant has to interrupt the original organization of the motor act, and to reprogram movement specifications in a short period of time in accordance with the new characteristics of the ball displacement.

Large-scale corrections to motor actions have been studied chiefly in aiming movements to spatial targets that abruptly have their position changed some time after the presentation of the primary target (1, $2,5,7,8,10,12,15)$. In this paradigm, the target is maintained at the same place in most trials, but in a small proportion of them the target is unexpectedly changed to another position during movement execution. In this condition, the probability of change in the target position represents one source of uncertainty in movement organization: the lower the probability of target change the higher the uncertainty on movement reprogramming. A second source of uncertainty in movement reprogramming is the direction of target change. Basically, the target can be displaced to previously known single direction, or be displaced to two or more directions nonanticipated by the performer. In the former situation some kind of anticipatory control might be used, while in the latter one is able to select the exact movement correction only after the target has been changed.

The effect of uncertainty on movement correction has been studied by Barrett and Glencross (1) using experimental conditions that required corrections to aiming movements at different moments after movement initiation. The main comparisons in this study involved two conditions: direction of target displacement known in advance by the participant, against uncertainty on direction of target displacement. The results indicated that the condition of unidirectional target displacement gave rise to earlier and more effective movement adjustments as compared with directional uncertainty. This finding revealed that reduced uncertainty on target change led to more efficient movement corrections. Yet, an additional finding worth noticing in the Barrett and Glencross' results was the continuous nature of movement amendments: the earlier the displacement of the target site before movement conclusion the more effective was movement correction in reducing spatial errors. Apparently, the corrective response does not prevail at once over the original movement organization, but gradually succeed in changing the action. Analogous results, indicating continuous movement reprogramming, have been found not only for aiming (18-20), but also for force control (13), handwriting (11), and interceptive tasks (21). In spite of some supportive empirical evidence for a continuous process of motor reprogramming, an alternative mode could be conceived: If inhibition of the original motor program and the specification of new program parameters are performed in a discrete parallel mode, large-scale corrections would be effective immediately after an interval equivalent to a reaction time period, which are approximately the same for both inhibitory and generative processes in motor control (14). Additionally, as in a parallel process movement reprogramming is supposed to be complete by the end of a reaction time period, we should see an abrupt transition between the profile of the original and the profile of the reprogrammed action around $200 \mathrm{~ms}$ after perturbation was detected. In the present study we investigated the role of two sources of uncertainty on movement timing reprogramming in an interceptive task. One source of uncertainty was probability of target velocity change, and the other was direction of target velocity change. For the former, we compared the probabilities of $25 \%$ and $50 \%$ of target velocity change, and for the latter we compared the condition of unidirectional change (increment or decrement) of target velocity against a condition in which target velocity could be increased or decreased in the same block of trials. In this sense, the experimental condition holding the lowest uncertainty was the combination of $50 \%$ of probability and unidirectional change, 
while the highest uncertainty was faced by the experimental condition of $25 \%$-bidirectional change. Our hypothesis was that the whole process of movement timing reprogramming is influenced by these two sources of uncertainty on target velocity change. If so, the time-span necessary for reacquiring the regular level of performance characteristic of unperturbed trials would be a function of uncertainty: the higher the uncertainty the longer the reprogramming time.

\section{MATERIAL AND METHODS \\ Participants}

Male $(\mathrm{n}=8)$ and female $(\mathrm{n}=8)$ university students, aged from 20 to 30 years $(M=23 ; S D=2,2)$, volunteered as participants. All of them reported normal or corrected-to-normal vision, and were naive to the purpose of the experiment. They took part in the study after signing an informed consent form, in accordance with Helsinki declaration.

\section{Instrument and task}

The equipment was designed to produce an anticipatory timing task requiring reprogramming of temporal parameters of the motor action at different moments before target interception. The apparatus consisted of a 2-m-long electronic trackway, holding a series of closed spaced infrared light emitting diodes (LEDs) arranged in line on the longitudinal axis of its upper side surface. Perception of motion of a luminous stimulus (target) was generated by a sequenced lightening of the LEDs from one extremity of the trackway to the other, with target motion being controlled through a microcomputer. At one extremity of the trackway there was a force transducer inside a tennis hemiball filled with plastic mass, which signaled to the computational system the time that the sensor was touched. The trackway was set horizontally and participants stood upright beside its extremity. The aim in the task was synchronizing the action of hitting the hemiball with the inner face of the fingers, through a movement like a soft tap, with the arrival of the moving target at the end of the trackway near the participant (Figure 1). Movement amplitude was not controlled, but all participants performed regularly the action mainly by a single flexion of the wrist, which made movements very short and similar across participants. This task was performed with the preferred hand. Ambient light was dimly lit, so that the target could be seen with good distinctiveness, without disturbing vision either of the target or of the active hand.

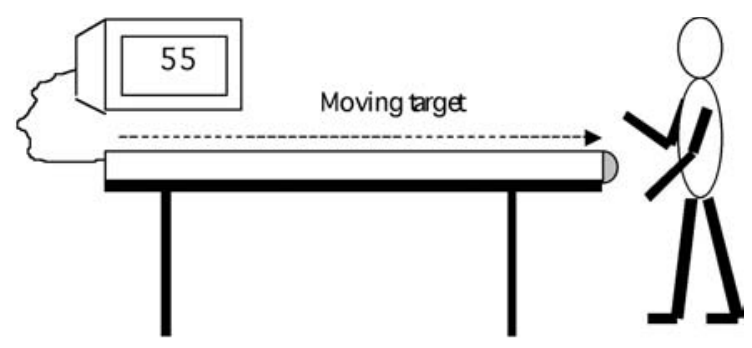

Figure 1: Schematic representation of the experimental set up.

\section{Experimental design and procedures}

Participants initially got acquainted with the task by performing a set of 15 trials with the luminous target coming through the trackway at a constant velocity of $3 \mathrm{~m} / \mathrm{s}$, and returning to the opposite end of the trackway at $1 \mathrm{~m} / \mathrm{s}$. Thus, the target was continuously going back and forth through the trackway, coming to the interception point at regular intervals of approximately $2.7 \mathrm{~s}$. During these trials participants were asked to assume a comfortable position and to test the necessary exertion of force on the hemiball in order to activate the transducer. The minimal force required for the transducer activation was very low, allowing for a soft manual contact. Yet, during this initial phase they were instructed about the way feedback would be supplied throughout the experiment. Large digits displayed on-line on the computer monitor screen, which was positioned beside the opposite end of the trackway, indicated magnitude of synchronization errors in a millisecond scale and its direction through positive or negative signs, respectively for late and early responses. Associated with visual information on error, auditory signs were also supplied through the microcomputer loudspeakers indicating bandwidths of $20 \mathrm{~ms}$ of temporal error, with each bandwidth represented by a particular sound. We used five bandwidths of error, independent of its direction (early or delayed responses): 0-20 ms, 21-40 ms, 41- 
$60 \mathrm{~ms}, 61-80 \mathrm{~ms}$ and over $81 \mathrm{~ms}$. This combined visual-auditory feedback information was provided after every trial throughout the experiment, in order to favor the highest performance in all experimental conditions. Following the familiarization trials, participants were provided with an additional set of 50 trials, which aimed at increasing accuracy and stability of performance at the task. Features of target displacement and experimental procedures were the same as those of the familiarization trials.

Subsequently to the practice trials, participants faced different conditions of uncertainty on target velocity alteration. In these situations the practiced target velocity, used to initiate every trial, could be changed instantaneously in different moments during the target approach to the participant. More specifically, in part of the trials target velocity could have been changed from $3 \mathrm{~m} / \mathrm{s}$ to $2 \mathrm{~m} / \mathrm{s}$ (unidirectional change), and in another part target velocity could have been changed either from $3 \mathrm{~m} / \mathrm{s}$ to $2 \mathrm{~m} / \mathrm{s}$ or from $3 \mathrm{~m} / \mathrm{s}$ to $4 \mathrm{~m} / \mathrm{s}$ (bidirectional change). The major difference between uni and bidirectional conditions was that in the former direction of velocity change was known before its occurrence, allowing for a preparation in advance of the corrective response. In the latter condition, participants had to decide after velocity change whether they had to speed up or slow down their manual movements in order to achieve synchronization with the arrival of the moving target.

In this velocity-alteration phase, participants were assigned to one of two groups: $25 \%$ or $50 \%$ probability of target velocity alteration. Sequence of trials under constant or changed velocity was computercontrolled and unpredictable to participants, but they were informed before their participation in a particular experimental condition about the probability of target velocity alteration, possible direction(s) of velocity alteration, and the place at the trackway that velocity could be modified. Alteration of velocity was produced instantaneously at one of five moments before the expected time of target arrival at the end of the trackway: 200, 250, 300, 350 , and $400 \mathrm{~ms}$. Velocity increment was used only with the purpose of creating a condition of bidirectional change of target velocity, and it will not be presented in the analysis. After velocity reduction the new times for the target arrival at the interception point increased from 100 to $200 \mathrm{~ms}$ by steps of $25 \mathrm{~ms}$. Such increments in the time to target arrival resulted in times to arrival after velocity reduction (TAVR) of 300, 375, 450, 525, and $600 \mathrm{~ms}$, respectively. Table 1 presents the induced errors of performance, which indicates the increment of time to target arrival at the interception position in relation to regular trials under constant velocity. The sequence of conditions related to velocity alteration, one constant velocity and five TAVRs, was counterbalanced across participants. Half the participants in each group began this phase in the unilateral condition and the other half in the bidirectional condition.

Table 1. Time before target velocity reduction, remaining time when velocity was maintained constant and when it was reduced (TAVR], and the respective performance errors if no adjustments were made to movements in conditions of target velocity reduction.

\begin{tabular}{|c|c|c|c|}
\hline $\begin{array}{l}\text { Time before } \\
\text { velocity } \\
\text { increment }[\mathrm{ms} \text { ] }\end{array}$ & $\begin{array}{c}\text { Remaining } \\
\text { time under } \\
\text { constant } \\
\text { velocity }(\mathrm{ms} \text { ) } \\
200\end{array}$ & $\begin{array}{l}\text { Time after } \\
\text { velocity } \\
\text { reduction- } \\
\text { TAVR (ms) } \\
300\end{array}$ & $\begin{array}{l}\text { Induced } \\
\text { error (ms) }\end{array}$ \\
\hline $41 ?$ & 250 & 375 & -125 \\
\hline $36 ?$ & 300 & 450 & $\cdot 150$ \\
\hline 317 & 350 & 525 & -175 \\
\hline 267 & 400 & 600 & .200 \\
\hline
\end{tabular}

The number of trials per block was established in order to achieve 10 representative values for analysis in each condition. In the main phase of the experiment, participants carried out 10 trials under certain constant velocity in the block of unidirectional velocity change and another set of 10 trials in the block of bidirectional velocity change. For the trials with probability of velocity alteration, the amount of trials in each experimental condition was: unidirectional50\% (Uni50), 20 trials; bidirectional-50\% (Bi50) and unidirectional-25\% (Uni25), 40 trials; and bidirectional-25\% (Bi25), 80 trials. Rest intervals of approximately $30 \mathrm{~s}$ were provided between blocks of trials. Temporal accuracy in this task was measured as a function of the difference in time between the arrival of the target at the last LED in the receiving end of the trackway and the time at which the participant made manual contact with the hemiball. Algebraic 
error indicates direction (positive sign = delayed responses; negative sign $=$ early responses) and magnitude of errors.

\section{RESULTS}

Performance on trials in which target velocity was maintained constant in conditions of certainty or uncertainty (possible velocity change, PVC) on velocity constancy was analyzed through a 2 (Probability) x 2 (Direction) x 6 (Condition: CV x PVC 200-400 ms) ANOVA with repeated measures on the last two factors. Results indicated significant main effects for Direction, $\underline{\mathrm{F}}(1,14)=34.88, \underline{\mathrm{P}}<$ 0.0001 , and Condition, $\underline{\mathrm{F}}(5,70)=4.70, \underline{\mathrm{P}}<0.001$, and a significant Probability by Direction interaction, $\underline{F}(1,14)=5.03, \underline{P}<0.05$. The main effect for direction was due to a lower overall algebraic error for the bidirectional $(4.2 \mathrm{~ms})$ as compared with unidirectional velocity change $(21.0 \mathrm{~ms})$. Post hoc contrasts through Newman-Keuls procedures indicated that the main effect for condition was due to significant differences between certainty on constant velocity and PVC at $250 \mathrm{~ms}$, and PVC at 200-250 ms vs. 350-400 ms. Decomposition of the probability by direction interaction indicated that the Uni50 condition presented higher positive errors than the other three experimental conditions. The Uni25 condition was significantly delayed in relation to $\mathrm{Bi} 25$, and fell short of significance in the comparison with Bi50 ( $\underline{\mathrm{P}}$ $=0.08)$. The bidirectional conditions did not differ from each other (Figure 2).

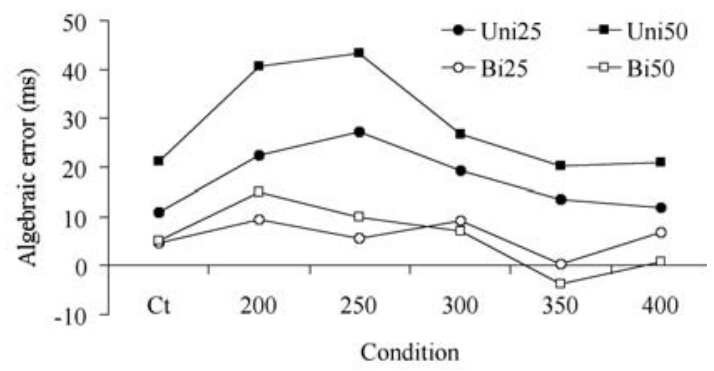

Figure 2. Algebraic error ( $\mathrm{ms}$ ) in trials under constant velocity as a function of probability $[25 \% \times 50 \%$ ] and direction [Uni x Bidirectional) of possible velocity change [Uni $x$ Bidirectional] for each PVC [200-400 ms]. Certainty on constant velocity $[\mathrm{Ct}]$ was presented as a base-line for comparison.
Algebraic errors in trials that target velocity was changed were analyzed through a three way 2 (Probability of velocity alteration: $25 \% \times 50 \%) \times 2$ (Direction: uni x bidirectional) x 6 (Condition of velocity alteration: certainty on constant velocity $\mathrm{x}$ TAVRs 300-600) ANOVA with repeated measures on the last two factors. The results indicated significant main effects for Direction, $\underline{\mathrm{F}}(1,14)=3.88, \underline{\mathrm{P}}<$ 0.001, and Condition, $\underline{\mathrm{F}}(5,70)=20.89, \underline{\mathrm{P}}<0.0001$, in addition to a significant interaction between Probability and Direction, $\underline{\mathrm{F}}(1,14)=21.89$, $\underline{\mathrm{P}}<$ 0.0005. Post hoc discriminant comparisons revealed that the main effect for condition was due to lower errors in constant velocity as compared with all conditions of changed velocity, and higher errors for TAVRs 300-375 in comparison with TAVRs 525-600. An overall lower mean for unidirectional (-29.2 ms) as compared with bidirectional $(-46.4 \mathrm{~ms})$ conditions was responsible for the main effect of direction, but the probability by direction interaction indicated that only a single condition led to reduced temporal errors: similar performance was found between conditions Uni25, Bi25, and Bi50, with all of them presenting higher negative errors (early responses) than the Uni50 condition (Figure 3). These findings showed that higher probability and unidirectionality of velocity change were effective in reducing temporal error only when these factors were combined in a single experimental condition. Therefore, these simple effects did not lead to any advantage regarding lower probability and bidirectionality of velocity alteration in combination (Bi25), which was expected to be the most restrictive condition for timing reprogramming.

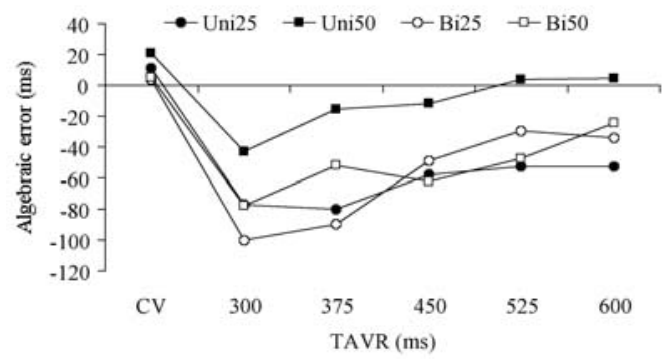

Figure 3. Algebraic error ( $\mathrm{ms}$ ) in trials that target velocity was maintained constant and when target velocity was reduced, as a function of probability [25\% $\times 50 \%$ ] and direction (Uni $\times$ Bidirectional] of velocity alteration for each time to arrival after target velocity reduction [TAVR, 300-600 ms]. Performance for constant velocity (CV) was presented as a base-line for comparison. 


\section{DISCUSSION}

Hypothetically, movement correction might be implemented in two ways, i.e. through a discrete or through a continuous transition between action parameter specifications. If movement timing was corrected in the former mode, we should see the reacquisition of the best level of timing accuracy immediately after the structural delay for initiation of movement amendments, which has been estimated to be around $200 \mathrm{~ms}$ in interceptive tasks $(9,12)$. Clearly, the results showed that this was not the case. Rather than a discrete transition from large to small temporal errors, we observed a strictly continuous recovery of the timing accuracy characteristic of the condition of certainty on constant velocity. This finding is in agreement with previous results suggesting that the sensorimotor system is unable to make accurate large-scale changes of movement specifications in short periods of time $(1,11,13,18$, $20,21)$. In this sense, these results show that under circumstances of reduced time to implement corrections to ongoing movements, action parameters are specified in the midway between the primary and the secondary target. Lack of a significant difference between rates of movement reprogramming for TAVRs 525 and $600 \mathrm{~ms}$, on the other hand, indicated stabilization of the reprogramming process in the last period. This implies that only limited, if any, supplementary gains in accuracy should be expected by providing extra time for movement adjustment. Such a time-dependent gradual recovery of timing accuracy in response to target velocity change supports the concept of competition between the corrective and original timing specifications put forth by Barrett and Glencross (1). Apparently, the initial timing specification is not inhibited at once to give place to a new specification, but rather progressively modified over time.

The finding of a continuous timing reprogramming is at odds with previous conceptualizations of a direct linkage between the visual and motor systems $(3-4,16)$. From this point of view, the performer observes the moving target up to a critical point at which the interceptive movement is triggered directly by an optical variable. From this moment onwards the ongoing movement is thought to be continuously adjusted on the basis of visual information throughout the remaining displacement of the moving target, without participation of slow perceptual processes. If this proposition was correct we should see a fast and accurate correction to movement timing right after target velocity transition. The relatively long delay of approximately $500 \mathrm{~ms}$ to complete movement reprogramming, on the contrary, suggests that such a transition between timing specifications is a higher order process in movement organization. In accordance with this interpretation, uncertainty on target velocity change was shown to be an important factor in determining the rate of timing accuracy recovery. The decreased rate of reprogramming for the experimental conditions holding higher uncertainty showed that a cognitive factor (expectancy) modulated the change of timing specification, making it less efficient particularly for lower probability of velocity transition. Analysis of temporal errors suggested that an improved rate of movement reprogramming is due to a more efficient transition between motor specifications. Apparently, a higher probability of velocity modification in a predetermined direction leads the motor system to a state of proneness to change the motor program that favors the replacement of the original movement specifications in a more accurate way. This higher efficiency for the Uni50 condition was maintained throughout the TAVRs studied, which shows that this effect is not restricted to the shortest TAVRs, having an enduring influence on timing reprogramming. From our results, an increased rate of movement reprogramming is achieved only by combining unidirectionality and higher probability of velocity change, while these components individually do not lead to any advantage in the reacquisition of the best timing accuracy in comparison with the Bi50 condition (highest uncertainty on velocity alteration). Interestingly, the three increased uncertainty conditions were unable to achieve a higher rate of timing correction in order to compensate for the larger error induced by target velocity modification. Under these conditions, individuals seem to establish an enlarged confidence on the original timing specification, which makes it more difficult to be replaced by another one when the environment so requires. It seems that knowing the direction of velocity change a priori has an adap- 
tive role only to the extent that an individual is prone to modify the timing specifications.

An additional point in the results worth commenting upon was the incomplete timing reprogramming for the conditions of increased uncertainty. Even after $600 \mathrm{~ms}$ the Uni25, Bi25, and Bi50 conditions were unable to reacquire their best level of timing accuracy observed under certain constant velocity, and achieve a performance similar to the Uni50 condition. This finding is indicative that reprogramming of movement timing in situations of increased uncertainty on target velocity change may bring about perturbations to movement organization that are not entirely dissipated over time. Beyond the theoretical interest in understanding this limitation in timing reprogramming, such an observation has applied implications for open sport settings wherein accurate interception of moving objects is the major aim to be achieved.

\section{Acknowledgments}

This project was supported by the Brazilian National Council for Science and Technology (CNPq), and the Foundation for Research Advancement of São Paulo, Brazil (FAPESP).

\section{CORRESPONDÊNCIA}

\section{Luis Augusto Teixeira}

Escola de Educação Física e Esporte

Universidade de São Paulo

Av. Prof. Mello Moraes, 65

05508-900 - São Paulo, S.P.

Brasil

lateixei@usp.br

\section{REFERENCES}

1. Barrett NC, Glencross DJ (1989). Response amendments during manual aiming movements to double-step targets. Acta Psychol 70: 205-217

2. Bock O, Jüngling S (1999). Reprogramming of grip aperture in a double-step virtual grasping paradigm. Exp Brain Res 125: 61-66

3. Bootsma RJ, Houbiers MHJ, Whiting HTA, Pieter CWW (1991). Acquiring an attacking forehand drive: the effects of static and dynamic environment conditions. Res $Q$ Exerc Sport 62: 276-284

4. Bootsma RJ, Wieringen PCW van (1990). Timing and attacking forehand drive in table tennis. J Exp Psychol Hum Percept Perform 16: 21-29

5. Boulinguez P, Nougier V (1999). Control of goal-directed movements: the contribution of orienting of visual attention and motor preparation. Acta Psychol 103: 21-45

6. Brenner E, Smeets JBJ, Lussanet MHE (1998). Hitting moving targets. Exp Brain Res 122: 467-474

7. Carnahan H, Goodale MA, Marteniuk RG (1993). Grasping versus pointing and the differential use of visual feedback. Hum Mov Sci 12: 219-234

8. Carnahan H, Marteniuk RG (1994). Hand, eye, and head coordination while pointing to perturbed targets. J Motor Behav 26: 135-146

9. Donkelaar PV, Lee RG, Gellman RS (1992). Control strategies in directing the hand to moving targets. Exp Brain Res 91: 151-161

10. Engel KC, Soechting JF (2000). Manual tracking in two dimensions. J Neurophysiol 83: 3483-3496

11. Galen GPV van, Weber JF (1998). On-line size control in handwriting demonstrates the continuous nature of motor programs. Acta Psychol 100: 195-216

12. Georgopoulos AP, Kalaska JF, Massey JT (1981). Spatial trajectories and reaction times of aimed movements: effects of practice, uncertainty, and change in target location. J Neurophysiol 46: 725-743

13. Hening W, Favilla M, Ghez C (1988). Trajectory control in targeted force impulses. V. gradual specifications of response amplitudes. Exp Brain Res 71: 16-128

14. Logan GD, Cowan WB (1984). On the ability to inhibit thought and action: a theory of an act of control. Psychol Rev 91: 295-327

15. Megaw ED (1974). Possible modification to a rapid ongoing programmed manual response. Brain Res 71: 425-441

16. Savelsbergh GJP, Whiting HTA, Bootsma RJ (1991). Grasping tau. J Exp Psychol Hum Percept Perform 17: 315-322

17. Soechting JF, Lacquaniti F (1983). Modification of trajectory of a pointing movement in response to a change in target location. J Neurophysiol 49: 548-564

18. Sonderen JF, Denier van der Gon JJ (1991). Reactiontime-dependent differences in the initial movement direction of fast goal-directed arm movements. Hum Mov Sci 10: 713-726

19. Sonderen JF, Denier van der Gon JJ, Gielen CCAM (1988). Conditions determining early modification of motor programmes in response to changes in target location. Exp Brain Res 71: 320-328

20. Sonderen JF, Gielen CCAM, Denier van der Gon JJ (1989). Motor programmes for goal-directed movements are continuously adjusted according to changes in target location. Exp Brain Res 78: 139-146

21. Teixeira LA, Lima ES, Franzoni MM (in press). The continuous nature of timing reprogramming in interceptive tasks. J Sport Sci 